\title{
Journal of Health Education and Health Promotion
}

\author{
www.journal.ihepsa.ir \\ Original Article
}

\section{Effectiveness of Frankl's Logotherapy on Health (Decreasing Addic- tion Potential and Increasing Psychological Well-being) of Students with Depression}

\section{Pridokht Esalati $^{1}, \underline{\text { Ali Arab }}^{2}$, Vali Mehdinezhad ${ }^{3}$}

1. PhD Student of Educational Psychology, Dept. of Psychology, Zahedan Branch, Islamic Azad University, Zahedan, Iran

2. Assistant Professor, Dept. of Psychology, Faculty of Educational Sciences and Psychology, University of Sistan and Baluchestan, Zahedan, Iran

3. Associate Professor, Dept. of Educational Sciences, Faculty of Educational Sciences and Psychology, University of Sistan and Baluchestan, Zahedan, Iran

\begin{tabular}{l}
\hline \multicolumn{2}{c}{ Article Information } \\
\hline \multicolumn{3}{l}{ Article History: } \\
Received: $\quad 2018 / 11 / 24$ \\
Accepted: $\quad 2018 / 12 / 24$ \\
Available Online: $2019 / 03 / 16$ \\
IJHEHP 2019; 7(1):84-92 \\
DOI: $\mathbf{1 0 . 3 0 6 9 9 / i j h e h p . 7 . 1 . 8 4}$
\end{tabular}

Corresponding Author:

\begin{abstract}
Ali Arab
Assistant Professor, Dept. of Psychology, Faculty of Educational Sciences and Psychology, University of Sistan and Baluchestan, Zahedan, Iran
\end{abstract}

Email:

aliarab@edpsy.usb.ac.ir

Use your device to scan and read the article onlin

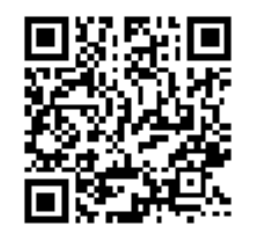

How to cite this article:

\section{Abstract}

Background and Objective: Depression is one of the most common psychological problems that can increase addiction potential and decrease psychological well-being. There are different methods to improve the psychological status of people and logotherapy is one of them. As a result, present research aims to determine effectiveness of Frankl's logotherapy on addiction potential and psychological well-being of girl students with depression.

Methods: This was a semi-experimental study with a pre-test and post-test design. The research population included girl students with depression in Farhangian University of Birjand Pardis in the 2017-18 academic years. 30 people were selected via available sampling method and were randomly assigned to two equal groups. The experimental group was trained for 8 sessions of 90 minutes (twice a week) using Frankl's logotherapy method. The instruments included the questionnaires of depression, addiction potential, and psychological well-being. The data were analyzed using t-test and MANCOVA methods.

Results: The findings showed that there was a significant difference between the two groups in terms of addiction potential and psychological well-being. In the other words, the Frankl's logotherapy significantly led to decreased addiction potential $(\mathrm{F}=57 / 10, P<0 / 001)$ and increased psychological well-being $(\mathrm{F}=73 / 36$, $P<0 / 001)$ of girl students with depression.

Conclusion: The results indicated the effectiveness of Frankl's logotherapy on decreasing addiction potential and increasing psychological well-being. Therefore, counselors and therapists can use Frankl's logotherapy method to decrease addiction potential and increase psychological well-being of girl students with depression.

Keywords: Logotherapy, Health, Addiction, Psychological well-being, Depression

Copyright (C) 2019 Journal of Health Education and Health Promotion. All rights reserved

Esalati, P., Arab, A., \& Mehdinezhad, V. (2019). Effectiveness of Frankl's Logotherapy on Health (Decreasing Addiction Potential and Increasing Psychological Well-being) of Students with Depression. Iranian Journal of Health Education and Health Promotion, 7 (1), 84-92

Iran J Health Educ Health Promot| فصلنامٔ علمى يزوهشى آموزش بهداشت و ارتقاى سلامت 


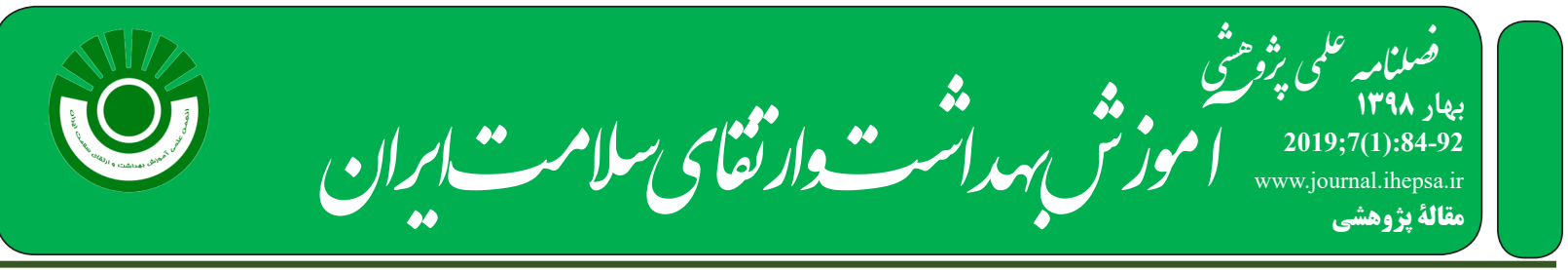

اثربخشى معنادرمانى فرانكل بر سلامت (كاهش آمادكى اعتياد و افزايش بهزيستى روانشناختى)

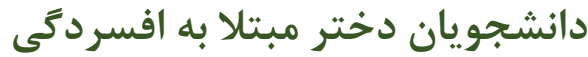

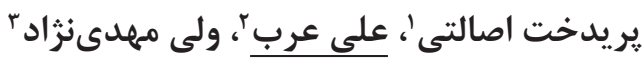

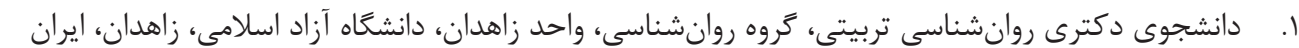

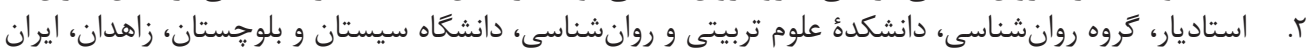

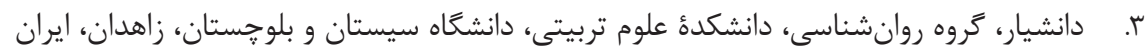

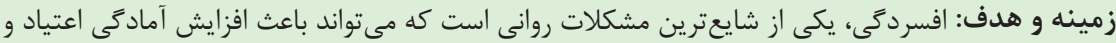

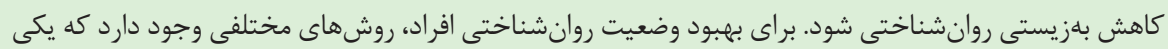

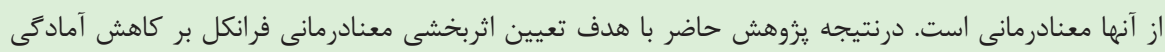

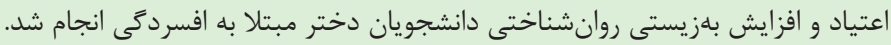

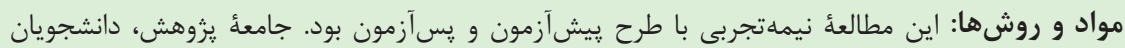

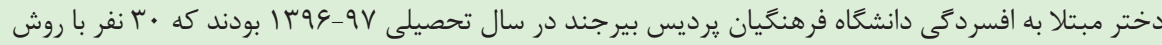

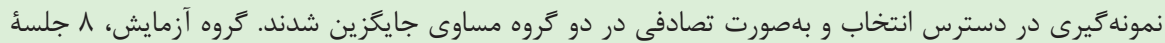

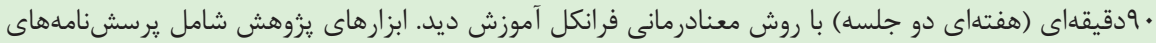

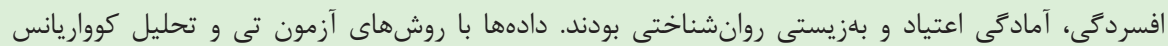

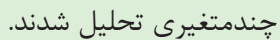

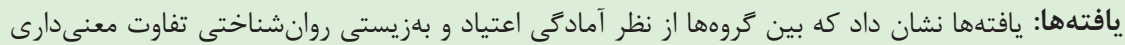

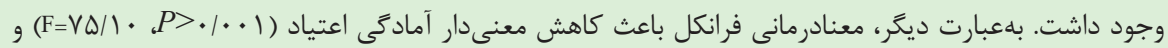

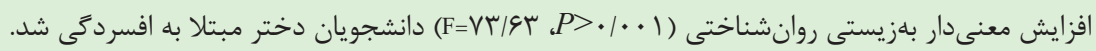
نتيجهَيرى: نتايج حاكى از اثربخشى معنادرمانى فرانكل بر كاهش آمادگى اعتياد و افزايش بلهزيستى

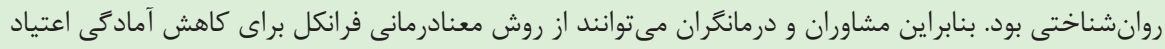

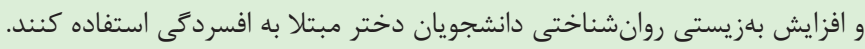
وازمهاى كليدى: معنادرمانى، سلامت، اعتياد، بهزيستى روانشناختى، افسردگى

كيىرايت ه: حق خاڤ، نشر و استفادة علمى از اين مقاله براى مجلئ آموزش بهداشت و ارتقاى سلامت محفوظ است.

\begin{tabular}{|c|c|}
\hline \multicolumn{2}{|c|}{ اطلاعات مقاله } \\
\hline & تاريخجِهُ مقاله \\
\hline $\mid r q \vee / \cdot q / \cdot r$ & دريافت": \\
\hline $\mid r q v / 1 \cdot / \cdot r$ & يذيرش: \\
\hline Irqv/Ir/ra & انتشار آنلاين: \\
\hline
\end{tabular}

IJHEHP 2019; 7(1):84-92

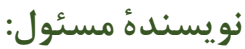

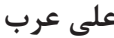
كروه روانشناسى، دانشكدئ علوم

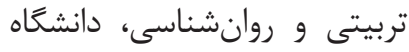
سيستان و وبلوجستان، زاهدان، تران ايران

يست الكترونيك: aliarab@edpsy.usb.ac.ir براى دانلود اين مقاله، كد زير را با باي

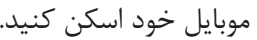

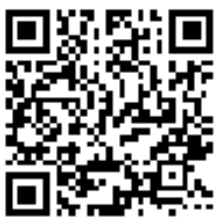

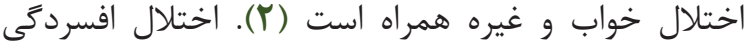

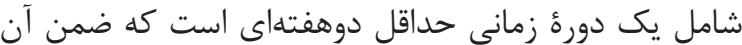

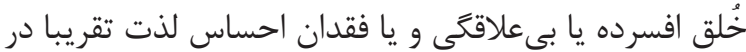

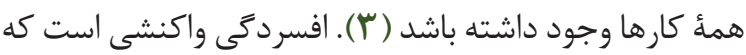

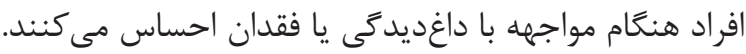

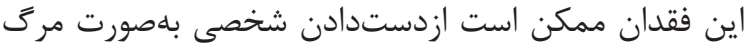

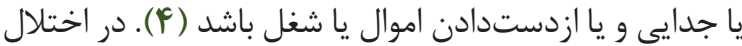

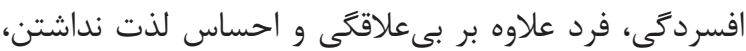

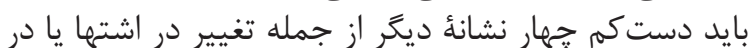

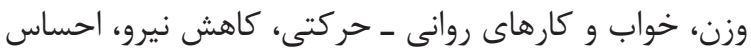

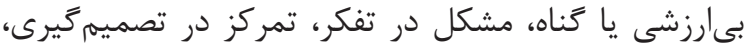

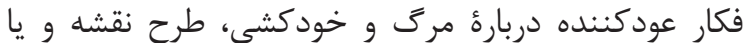

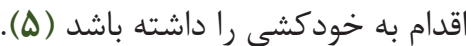

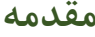

دانشجويان، بلويزه دانشجويان ساكن خوابخاههاى

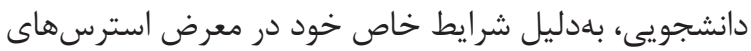

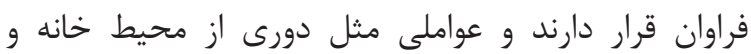

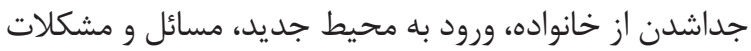

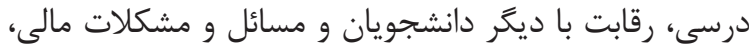

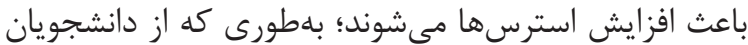

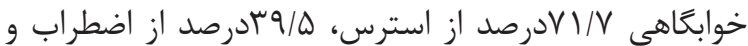

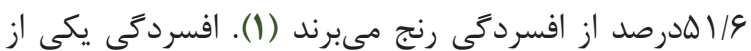

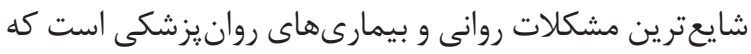

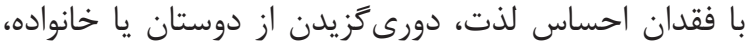

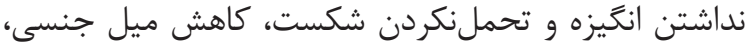

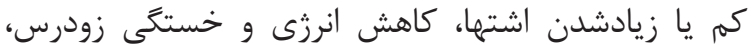


را به او يادآورى مى كند (If). از نظر Frankl در رويكرد

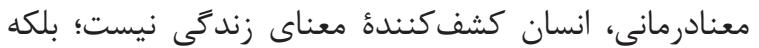

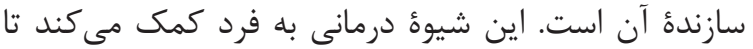

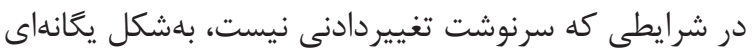

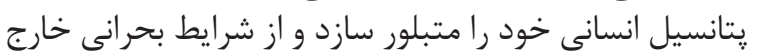

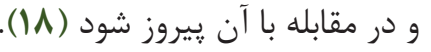

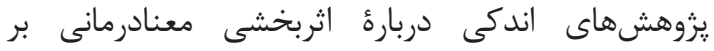

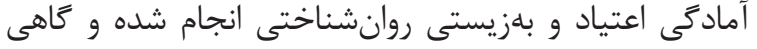

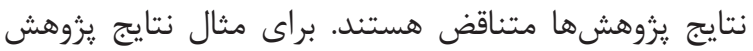

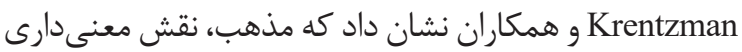

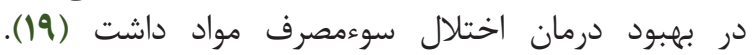

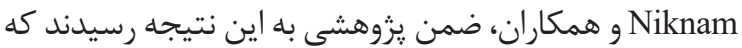

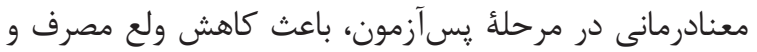

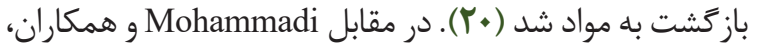

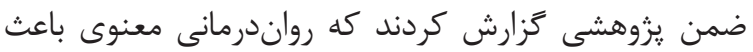

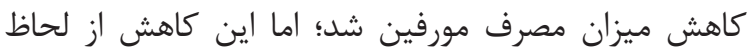

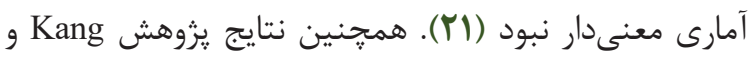

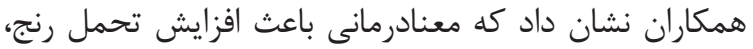

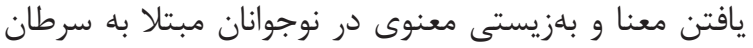

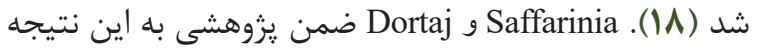

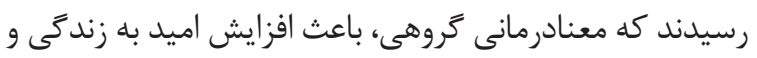

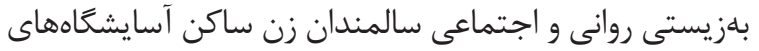

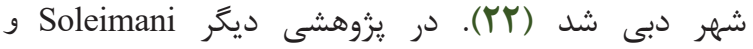
Khosravani

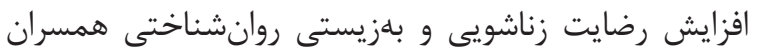

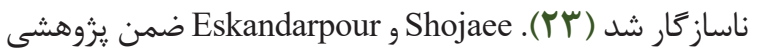

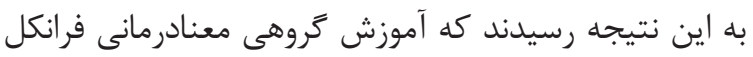
باعث افزايش بهزيستى روانشناختى و شادكامى دانش آمريد آموزان

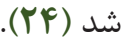

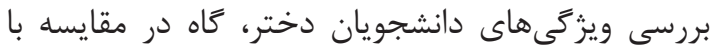

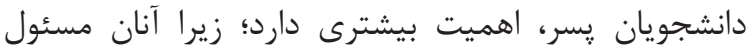

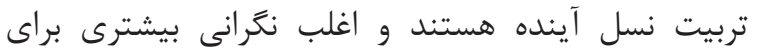

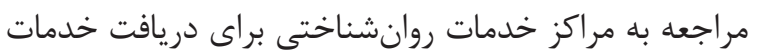

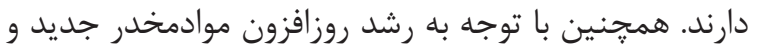

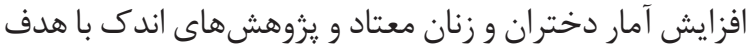

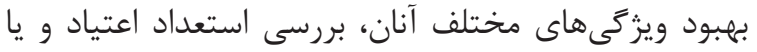

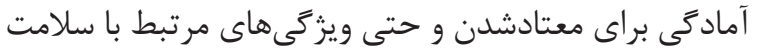

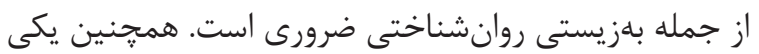

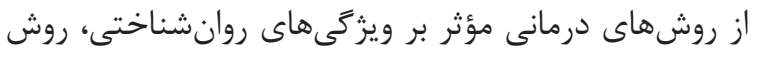

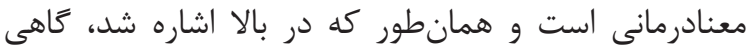

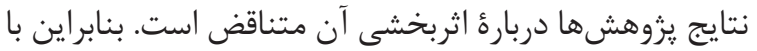

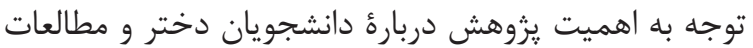

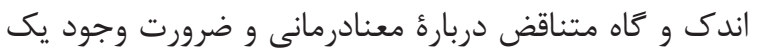

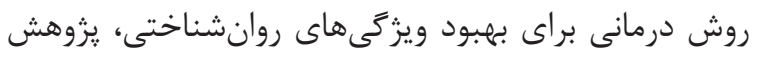

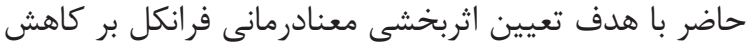

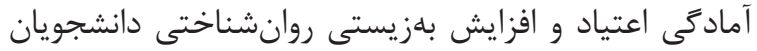
دختر مبتلا به افسردى انجى انجام شد.

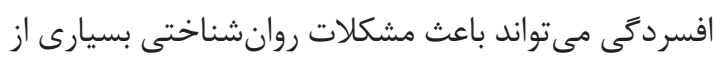

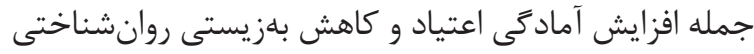

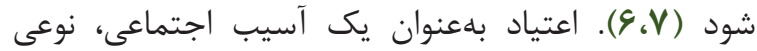

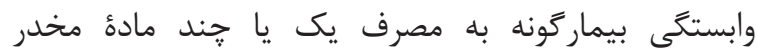

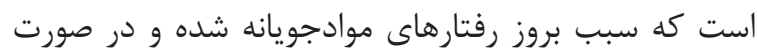

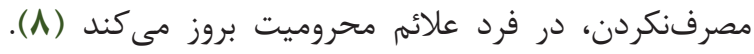

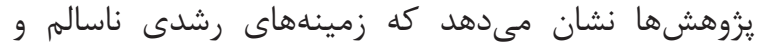

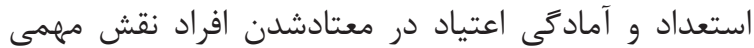

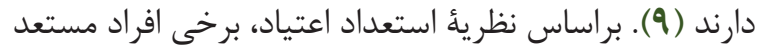

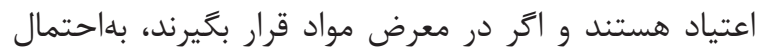

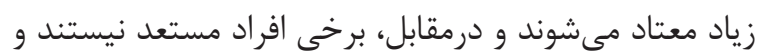

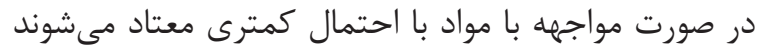

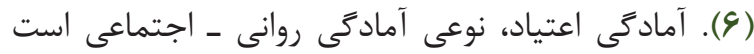

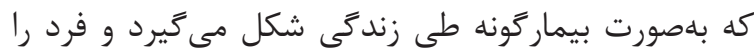

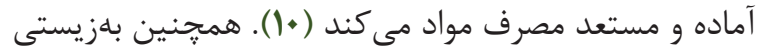

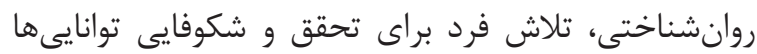

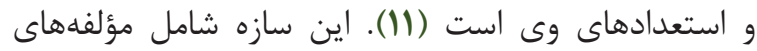

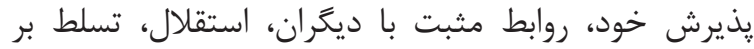

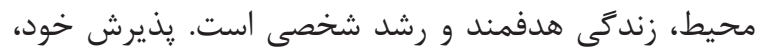

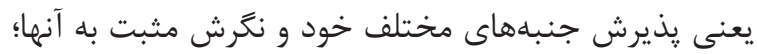

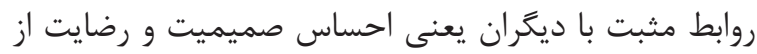

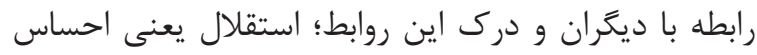

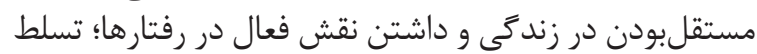

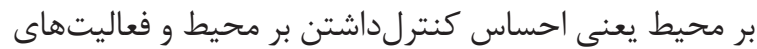

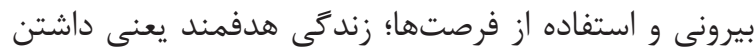

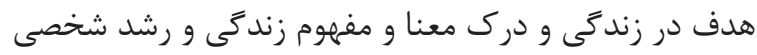

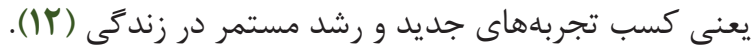

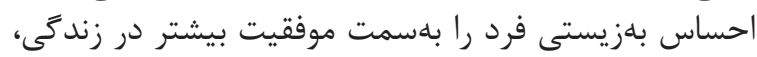

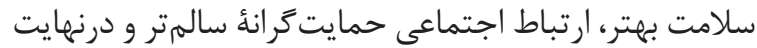

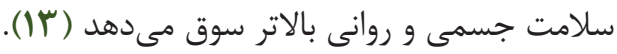

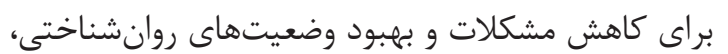

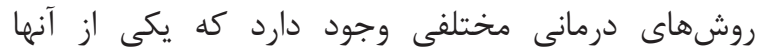

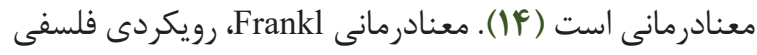

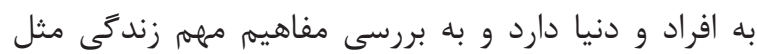

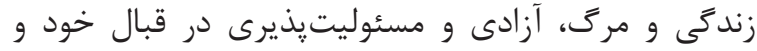

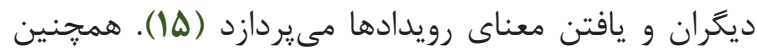

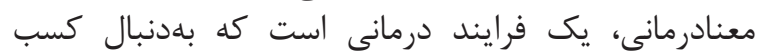

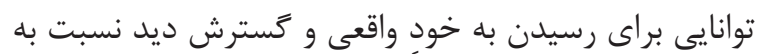

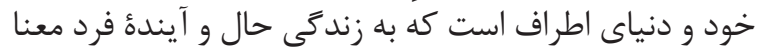

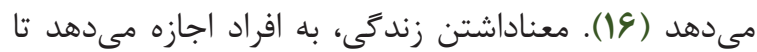

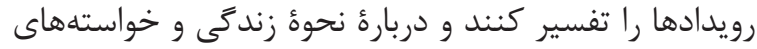

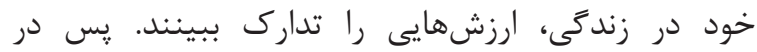

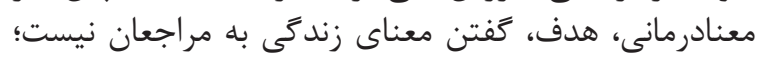

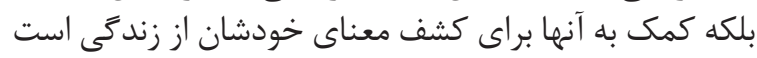

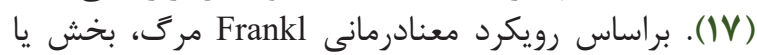

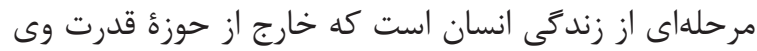

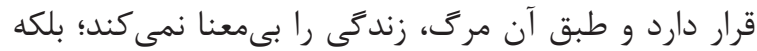

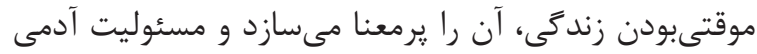




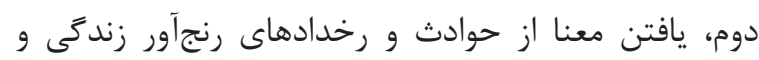

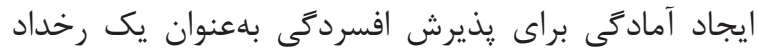

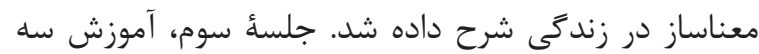

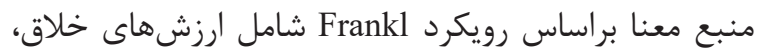

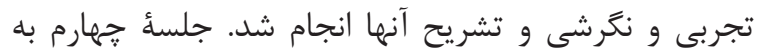

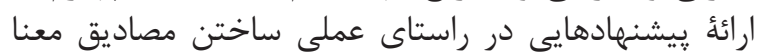

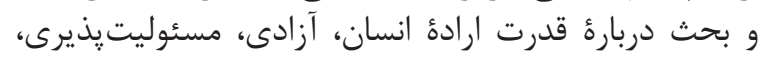

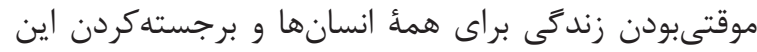

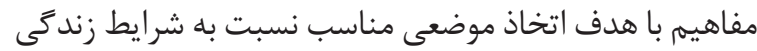

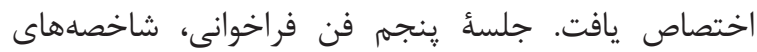

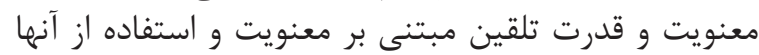

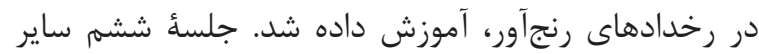

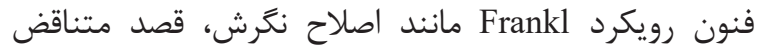

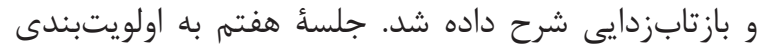

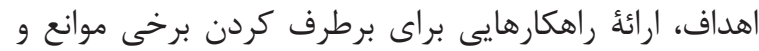

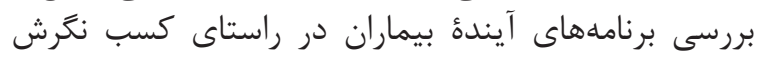

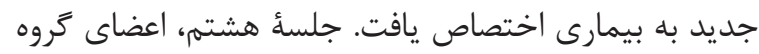

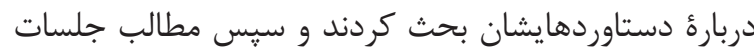

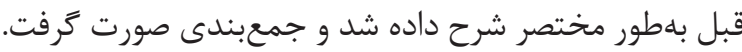

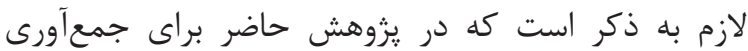
دادهها از ابزارهاى زير استفاده شد.

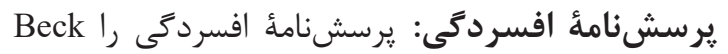

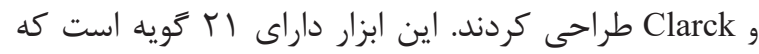

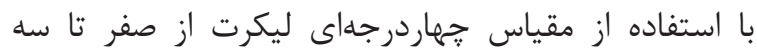

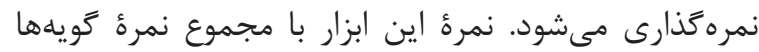

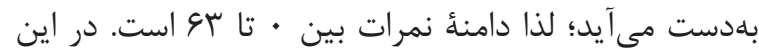

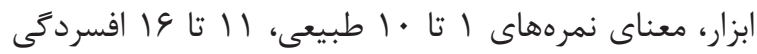

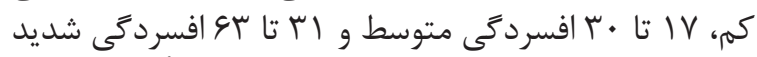

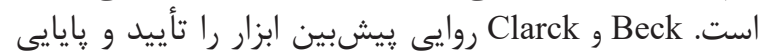

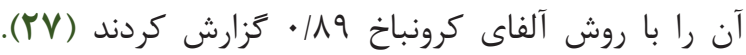

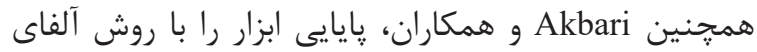

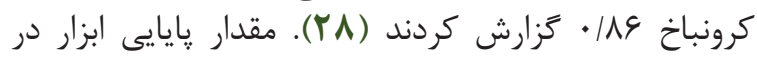

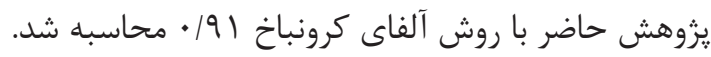

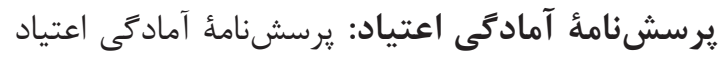

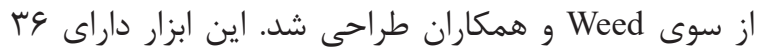

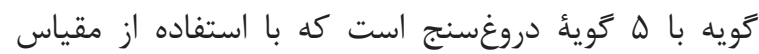

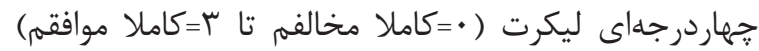

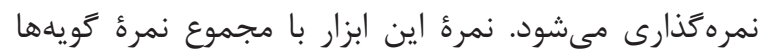

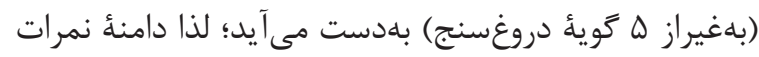

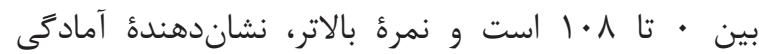

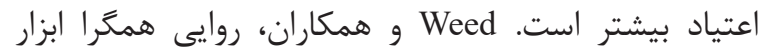

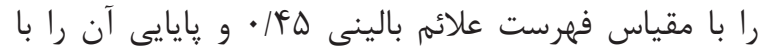

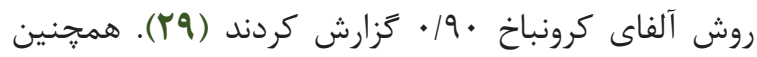
Mohammadkhani

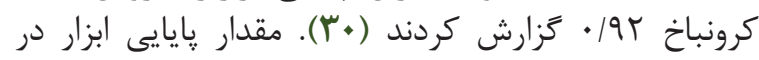

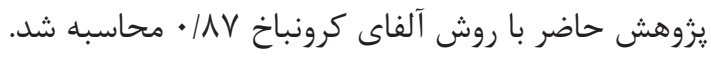

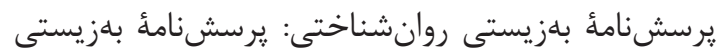

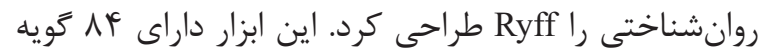

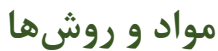

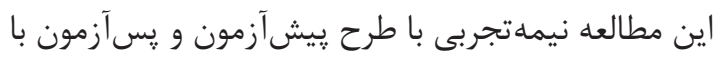

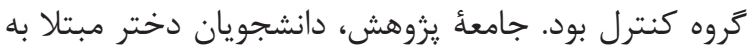

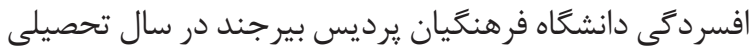
S99-9V

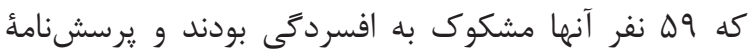

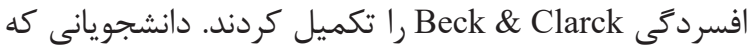

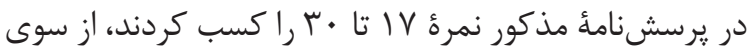

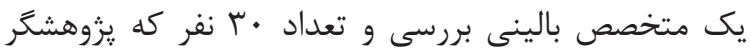

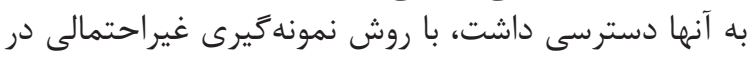

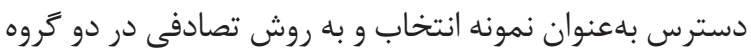

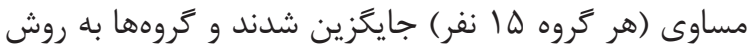

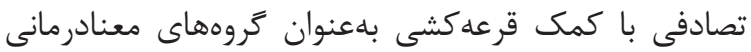

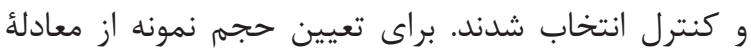

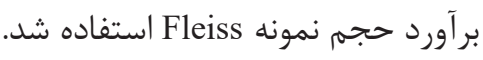
$n=\frac{2 \sigma^{2}\left(Z_{1-\frac{\alpha}{2}} Z_{1-\beta}\right)^{2}}{d^{2}}=\frac{2(1 / 53)^{2}(1 / 96+1 / 28)^{2}}{4 / 507}=\frac{4 / 6818 * 10 / 4976}{4 / 507}=10 / 90$ در اين معادله، براساس يزوهش

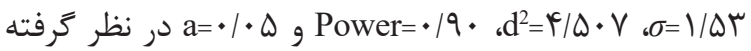

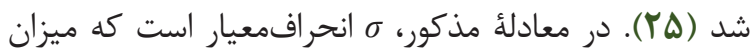

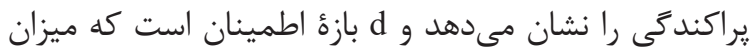

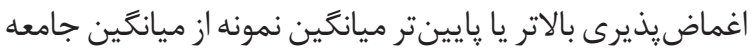

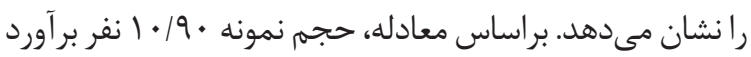

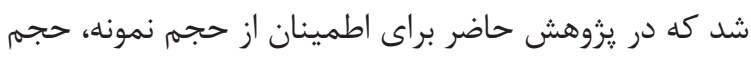

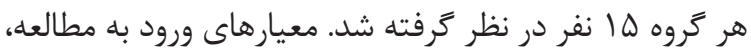

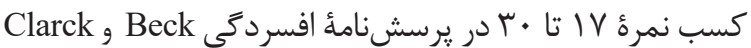

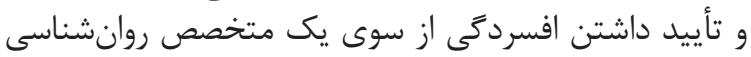

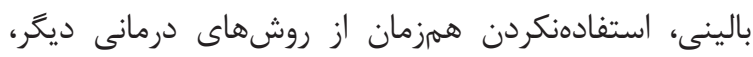

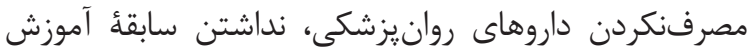

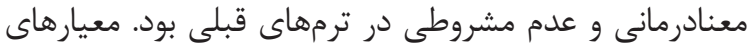

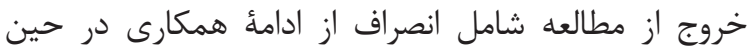

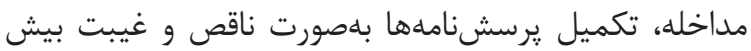

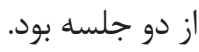

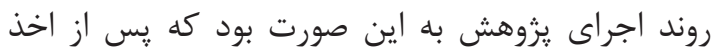

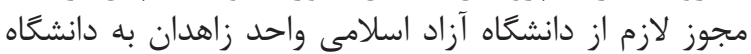

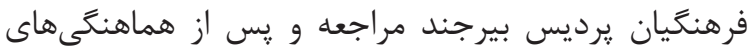

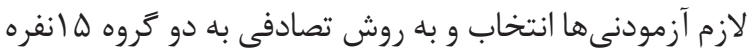

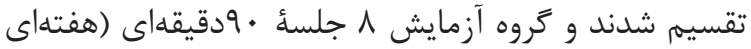

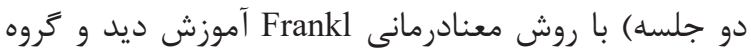

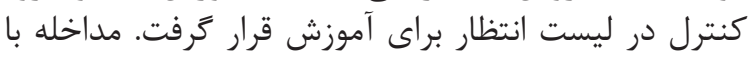

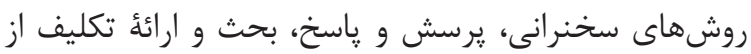

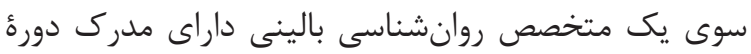

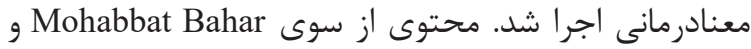

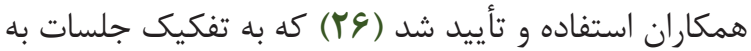

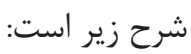

جلسهُ اول به آشنايى درمانكر و اعضاى كَروه بـ با يكديكر،

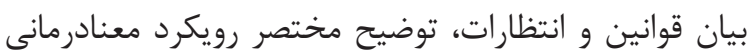

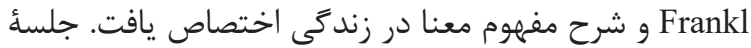


انحرافمعيار براى توصيف نحوه توزيع متغيرها و در سطح

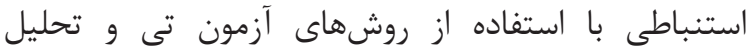

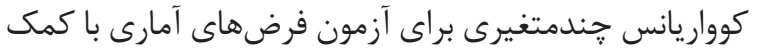

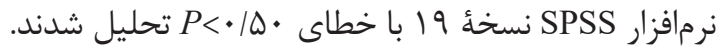

\section{يافته ها}

آزمودنى هاى • r دانشجوى دختر (ه ا نفر گروه معنادرمانى

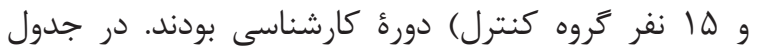

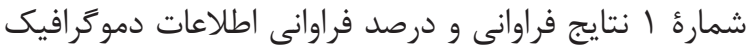

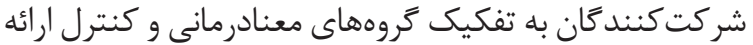

در جدول شمارة 1 نتايج فراوانى و درصد فراوانى مأى

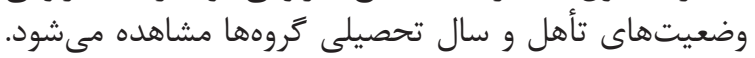

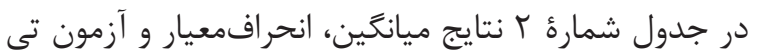

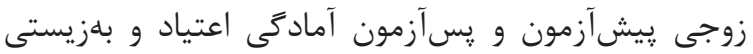

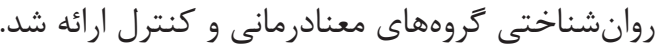

است كه با استفاده از مقياس ششدرجهاى ليكرت (

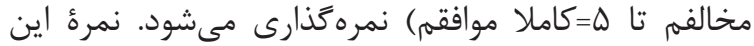

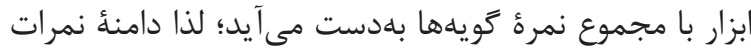

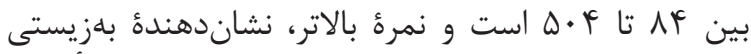

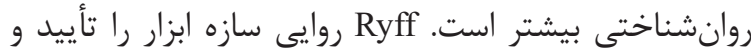

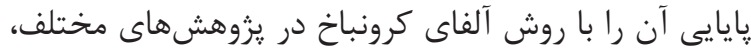

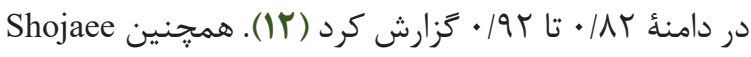

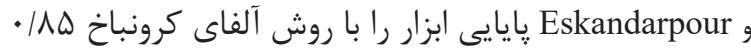

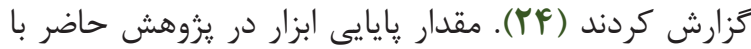

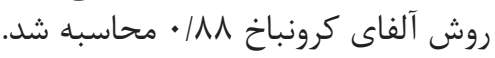

در زيزوهش حاضر، رعايت نكات اخلاقى از جمله

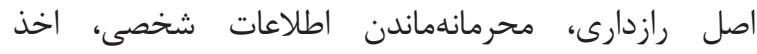

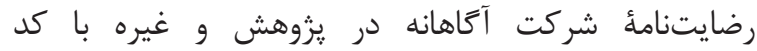

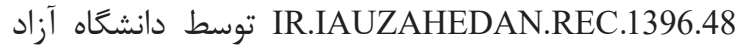

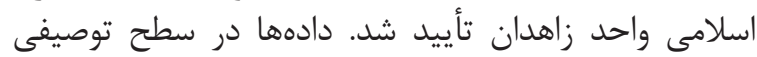
با استفاده از شاخصهاى فراوانى، درصد فراوانى، ميانگين و

جدول شمارهٔ ا. نتايج فراوانى و درصد فراوانى اطلاعات دموكر افيك شركتكنندًان به تفكيك تروههاى معنادرمانى و كنترل

\begin{tabular}{|c|c|c|c|c|c|}
\hline \multicolumn{2}{|c|}{ كروه كنترل } & \multicolumn{2}{|c|}{ كروه معنادرمانى } & \multirow[t]{2}{*}{ طبقات } & متغيرها \\
\hline درصد فراوانى & فراوانى & درصد فراوانى & فراوانى & & \multirow{3}{*}{ وضعيت تأهل } \\
\hline $1 \cdots$ & 10 & $1 \cdots$ & 10 & مجرد & \\
\hline$\cdot$ & $\cdot$ & $\cdot$ & $\cdot$ & متأهل & \\
\hline$r \cdot$ & $r$ & r\&|9V & f & سال اولى & \multirow{4}{*}{ وضعيت سال تحصيلى } \\
\hline T\&/9V & r & $r \cdot$ & r & سال دومى & \\
\hline f. & 4 & سז/ח & $\Delta$ & سال سومى & \\
\hline سT/M & $r$ & $r$. & r & سال :هارمى & \\
\hline
\end{tabular}

جدول شماره r. نتايج ميانكَين، انحر افمعيار و آزمون تى زوجى بِيش آزمون و پِّ آزمون آمادكى اعتياد و بهزيستى روانشناختى

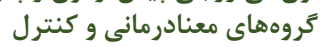

\begin{tabular}{|c|c|c|c|c|c|c|c|}
\hline \multirow[t]{2}{*}{ معنى دارى } & \multirow[t]{2}{*}{ آزمون T } & \multicolumn{2}{|c|}{ يسآزمون } & \multicolumn{2}{|c|}{ بيشآزمون } & \multirow[t]{2}{*}{ متغيرها } & \multirow[t]{2}{*}{ كرو } \\
\hline & & انحراف معيار & ميانگَين & انحراف معيار & ميانگين & & \\
\hline$\cdot / \cdot 1$ & $r \Delta / V I$ & F/Tr & $F F / T$. & $9 / 94$ & $\Delta r / \Lambda \varphi$ & آمادكى اعتياد & \multirow{2}{*}{ كروه معنادرمانى } \\
\hline$\cdot 1 \cdot \cdot 1$ & - Tr/gF & rN/VA & rیr/ll & $r \Delta / T_{1}$ & $r \cdot V / T r$ & بهزيستى روانشناختى & \\
\hline$\cdot / \Delta \Lambda r$ & $-\cdot / T r$ & glgt & $\Delta T / F T$ & $9 / \wedge$ & $\Delta I / V F$ & آمادكى اعتياد & \multirow{2}{*}{ كروه كنترل } \\
\hline.$/ 148$ &.$/ 9$ & TY/T & $r \cdot r / V I$ & $T F / T V$ & $r / 9 / 90$ & بهزيستى روانشناختى & \\
\hline
\end{tabular}

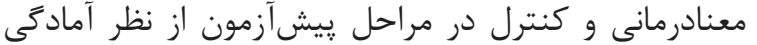

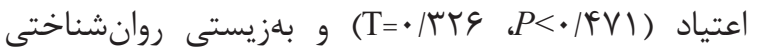
تفاوت معنى دارى نداشتند. همجنين (T=•/V9D،

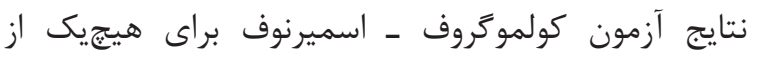

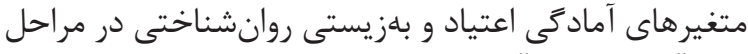

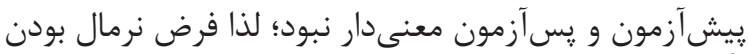

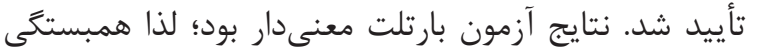
كافى بين متغيرهاى وابسته براى تحليل نتائ وجود داشت داشت. علاوه
طبق نتايج جدول شماره ז، نتايج آزمون تى زوجى

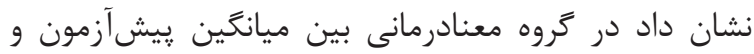

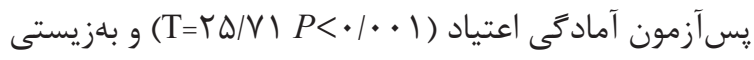

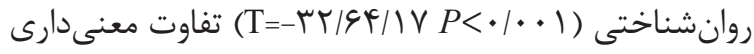

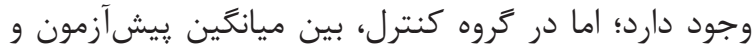

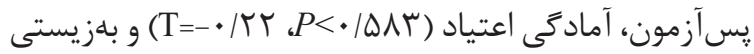

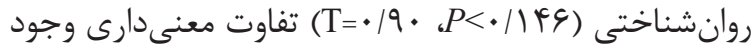

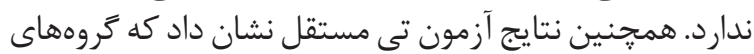


طبق نتايج جدول شمارة أل، بين گروهها در هر دو متغير

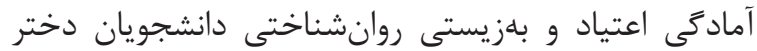

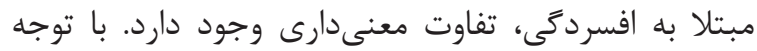

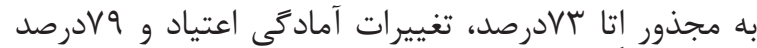

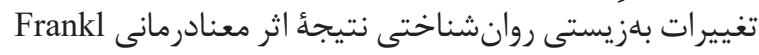

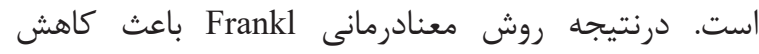

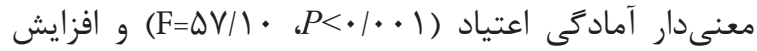

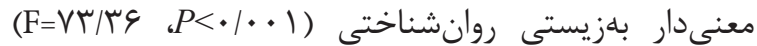
دانشجويان دختر مبتلا به افسردكى شد.

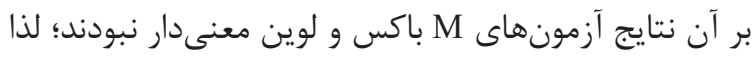

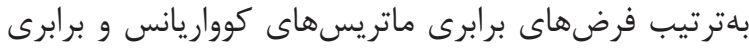
واريانسها تأييد شدند. بنابراين شرايط ائريس استفاده از تحائ تحليل

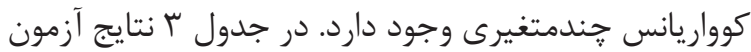
تحليل كوواريانس جندمتئغيرى ارائه شد.

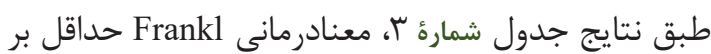

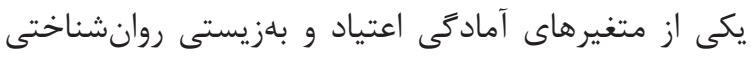

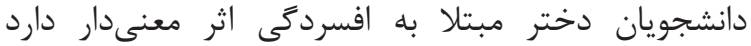

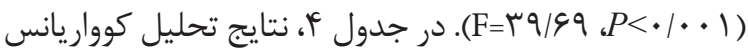

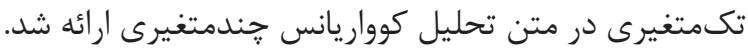

جدول شماره r. نتايج آزمون تحليل كوواريانس حندمتغيرى

\begin{tabular}{|c|c|c|c|c|c|}
\hline مجذور إِا & معنى دارى & F Fاره F F & مقدار & نوع آزمون & متغير مستقل \\
\hline - IAT & $.1 \cdot \cdot 1$ & ५q/दq & • & اثر پيلايى & معنادرمانى \\
\hline
\end{tabular}

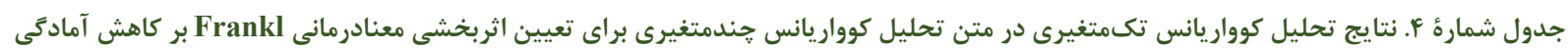

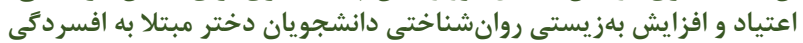

\begin{tabular}{|c|c|c|c|c|c|c|c|}
\hline مجذور إِا & معنى مارى & F آماره F & ميانگين مجذورات & آزادى & مجموع مجذورات & منبع اثر & متغيرهاى وابسته \\
\hline \multirow[t]{2}{*}{$\cdot / N r$} & $\cdot 1 \cdot \cdot 1$ & $\Delta V / l$ & $|F F| / M$ & 1 & $|F F| / \Lambda \Lambda$ & بين خروهى & آمادگى اعتياد \\
\hline & & & $r \Delta / r \Delta$ & TQ & GDSIDT & درون گروهى & \\
\hline \multirow[t]{2}{*}{$\cdot / v 9$} & $\cdot 1 \cdot \cdot 1$ & VTr & $r|\Delta \Delta| / \cdot 9$ & 1 & $r|\Delta \Delta| / \cdot q$ & بين زروهى & \multirow{2}{*}{ لهزيستى روانشناختى } \\
\hline & & & rq५/VV & rq & VGTN/·r & درون گروهى & \\
\hline
\end{tabular}

مورفين نشد (Y) (Y). در تبيين ناهمسويى نتايج اين يروهش

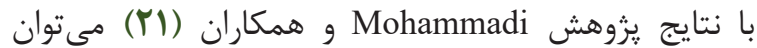

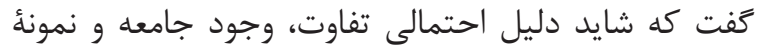

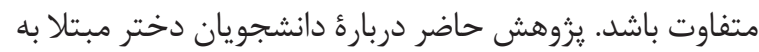

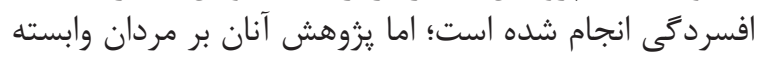

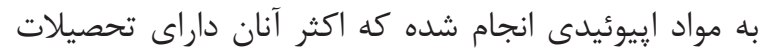

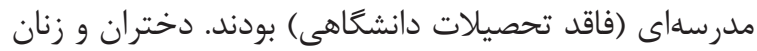

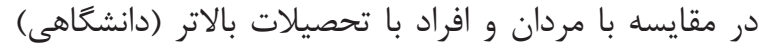

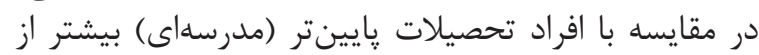

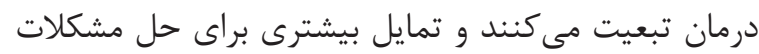

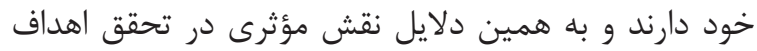

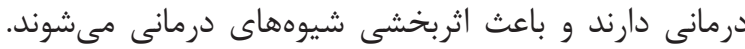

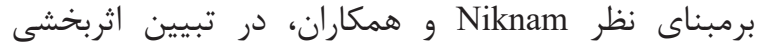

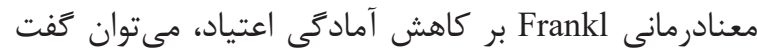

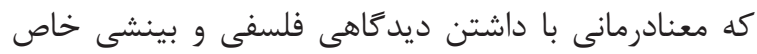

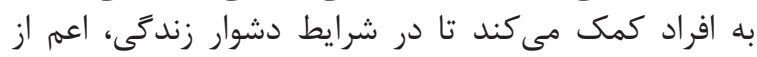

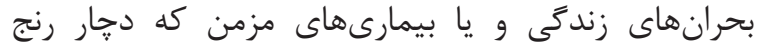

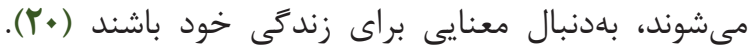

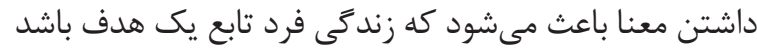

\section{بحث}

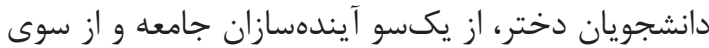

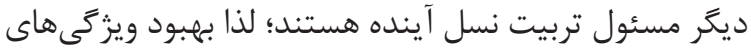

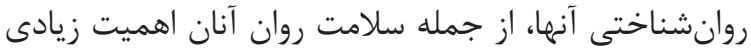

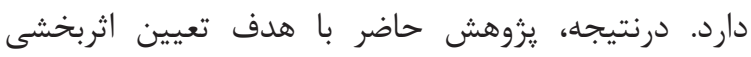

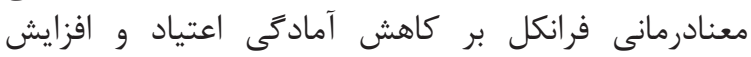

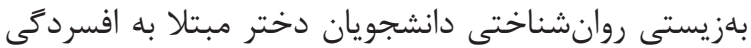

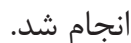

نتايج حاكى از اثربخشى معنادرمانى Frank1 بر كاهش

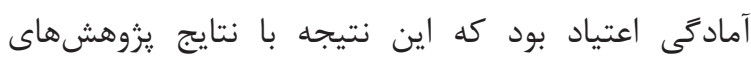
Krentzman

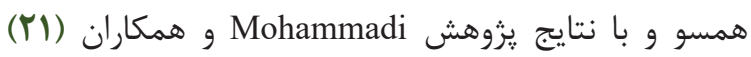

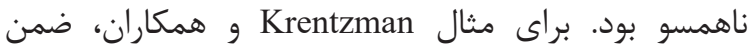

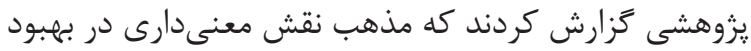

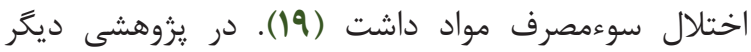
Niknam

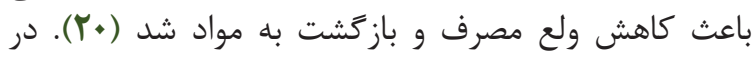

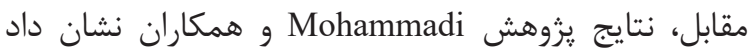
كه رواندرمانى معنوى باعث كاهش معنى دهار ميزان مصرف 
قدرت تصميمَيرى در بحرانها و مقابلة موفق با فشارهاى

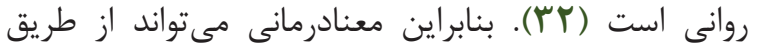

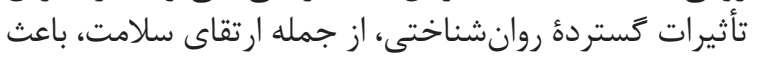

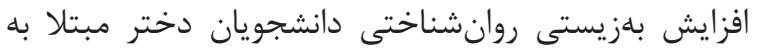

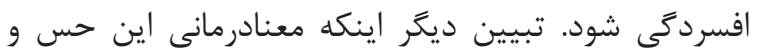

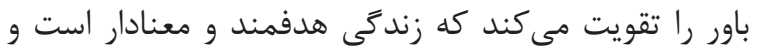

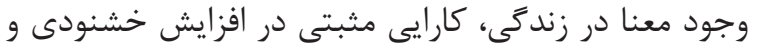

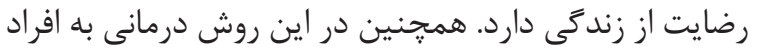

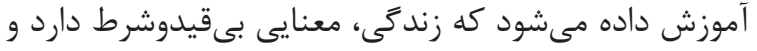

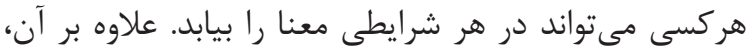

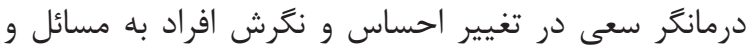

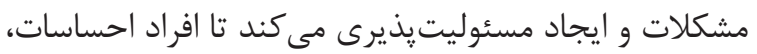

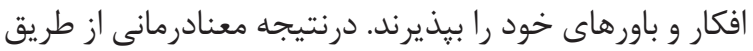

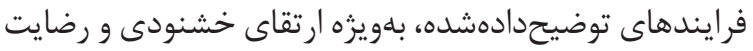

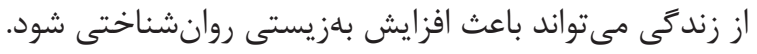
يزوهش حاضر با نقاط ضعف يا محدوديتهايى مواجه

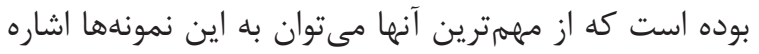

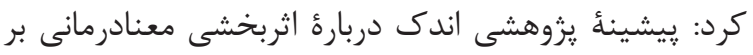

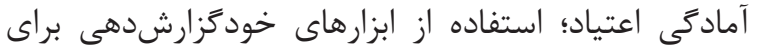

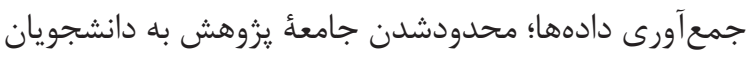

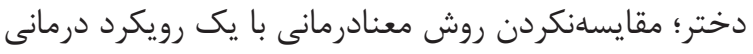

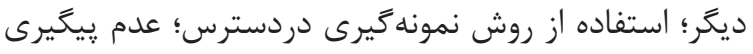

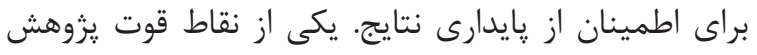

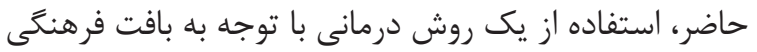

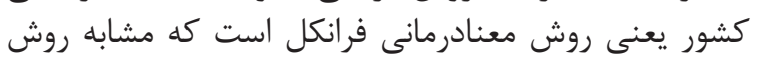

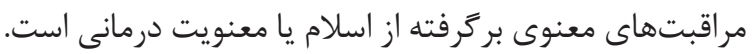

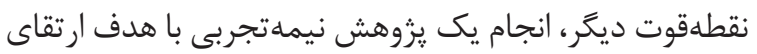

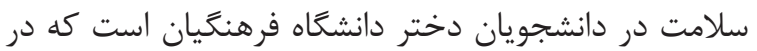

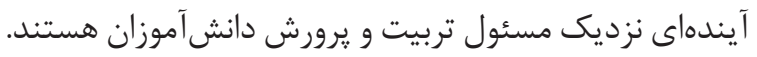

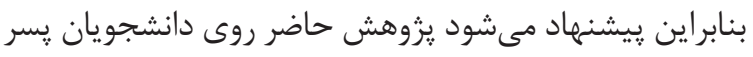

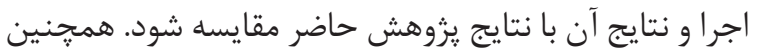

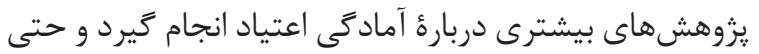

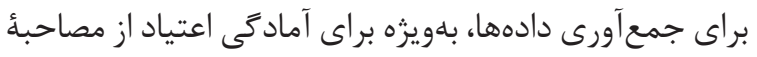

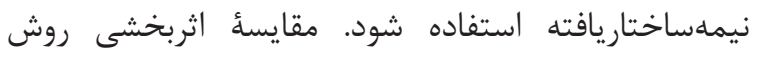

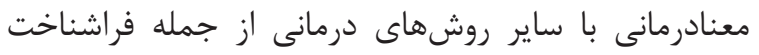

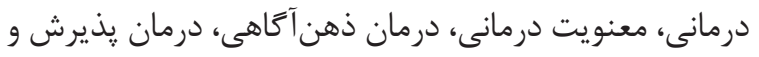

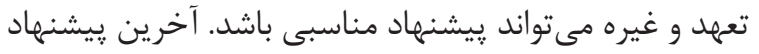

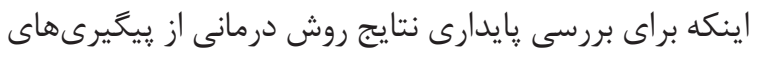
دو، جهار و يا حتى ششماهي استفادي بادي شود.

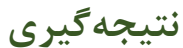

بلهور كلى نتايج نشان داد كه معنادرمانى Frankl باعث

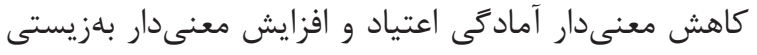

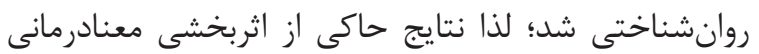

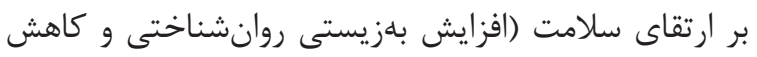

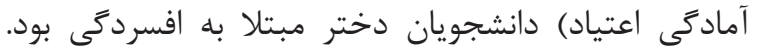

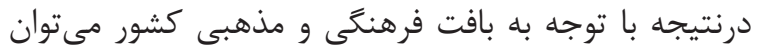

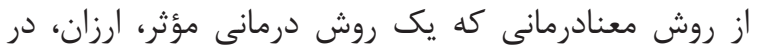

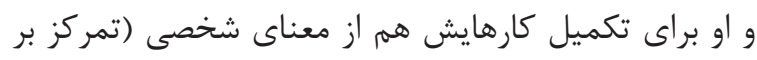

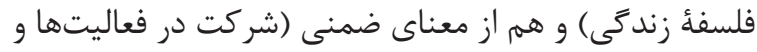

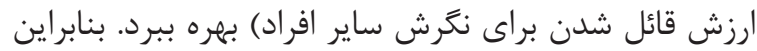

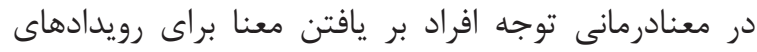

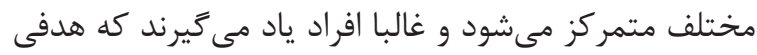

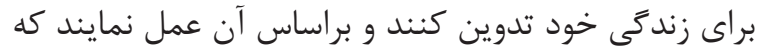

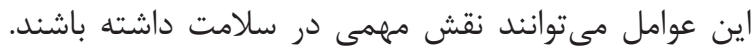

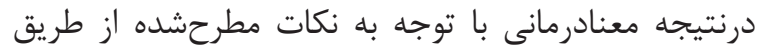

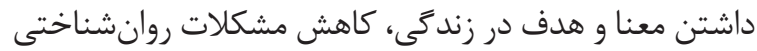

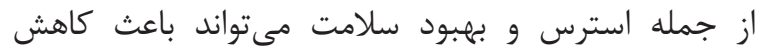

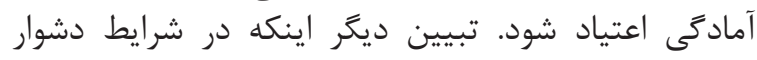

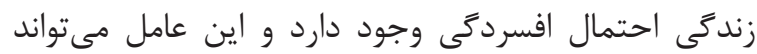

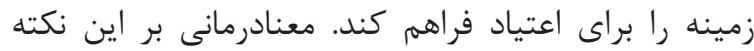

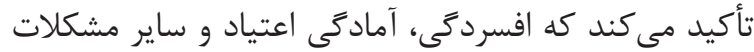

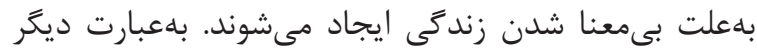

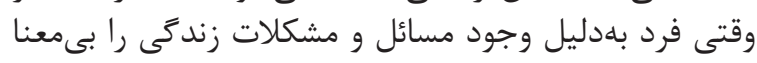

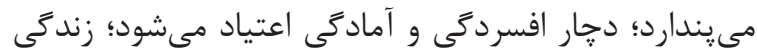

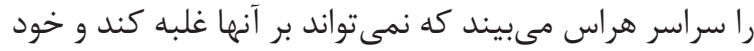

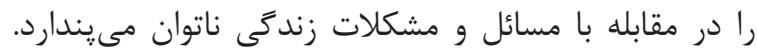

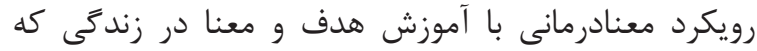

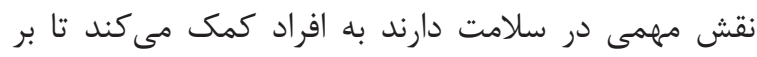

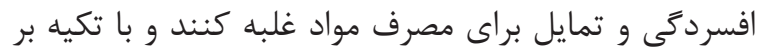

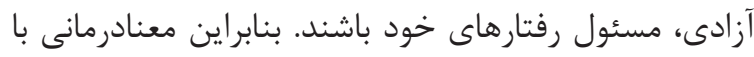

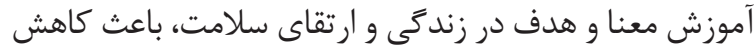

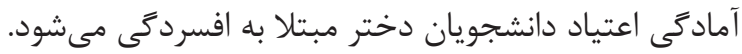

همجنين نتايج حاكى از اثربخشى معنادرمانى Frankl

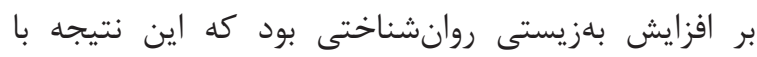

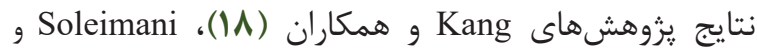

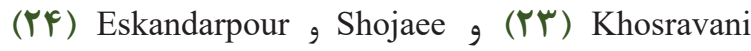

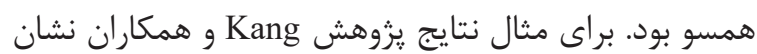

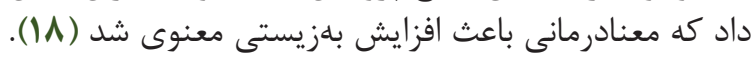

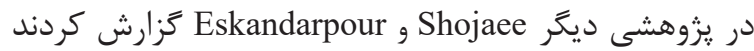

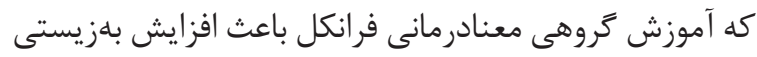

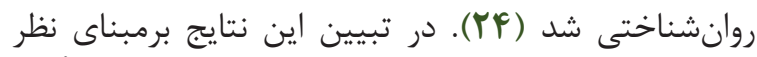

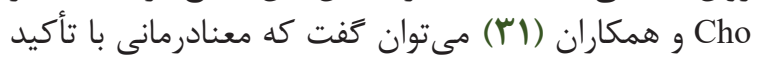

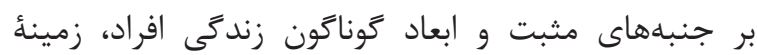

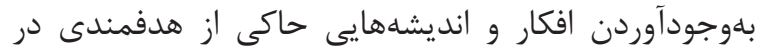

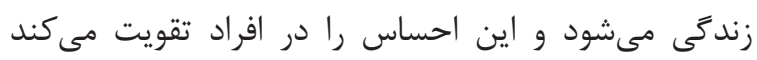

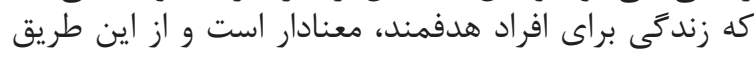

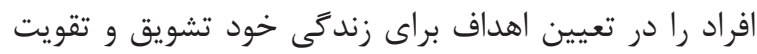

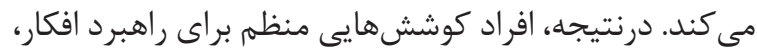

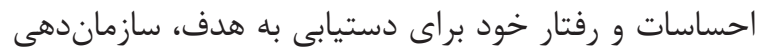

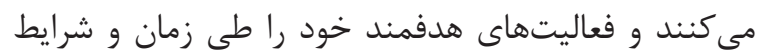

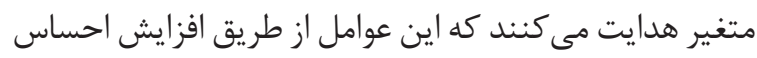

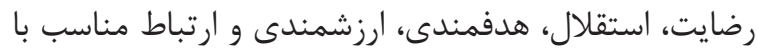

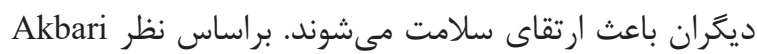

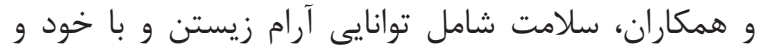

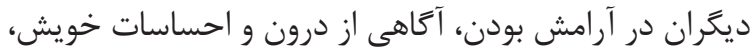




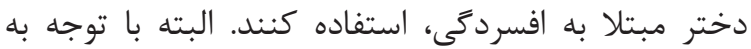

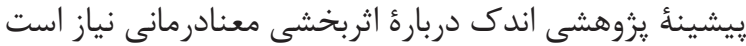

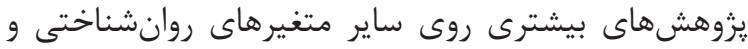

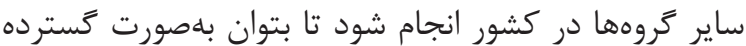

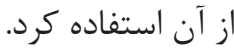

$$
\begin{aligned}
& \text { سياسگزارى }
\end{aligned}
$$

اين مقاله بركرفته از رساله دكترى روانشناسى دان دانشكاه

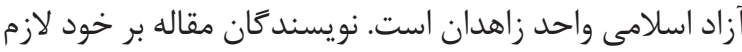

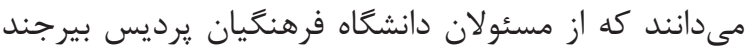

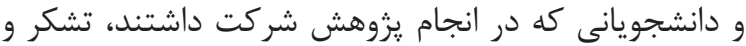

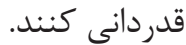

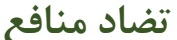

بين نويسندكان مقاله، هيج تضادى كزارش نشده است.

\section{References}

1. Dehdari T, Yarahmadi R, Taghdisi MH, Daneshvar R, AhmadPoor J. Relationship between meaning in life and depression, anxiety and stress status among college students of Iran university of medical sciences In 2013. Iran J Health Educ Health Promot. 2013; 1(3): 83-92.

2. Xiang X, Leggett A, Himle JA, Kales HC. Major depression and subthreshold depression among older adults receiving home care. Am J Geriatr Psychiatry. 2018; 26(9): 939-49. https://doi. org/10.1016/i.jagp.2018.05.001

3. Christensen GT, Maartensson S, Osler M. The association between depression and mortality - a comparison of survey- and register-based measures of depression. J Affect Disord. 2017; 210: 111-4. https://doi.org/10.1016/j.jad.2016.12.024

4. Banzhaf C, Hoffmann F, Kanske P, Fan Y, Walter $\mathrm{H}$, et al. Interacting and dissociable effects of alexithymia and depression on empathy. Psychiatry Res. 2018; 270: 631-8. https://doi. org/10.1016/j.psychres.2018.10.045

5. Liew H, Gardner S. The interrelationship between smoking and depression in Indonesia. Health Policy Technol. 2016; 5(1): 26-31. https:// doi.org/10.1016/j.hlpt.2015.10.003

6. Fatseas M, Serre F, Swendsen J, Auriacombe M. Effects of anxiety and mood disorders on craving and substance use among patients with substance use disorder: An ecological momentary assessment study. Drug Alcohol Depend. 2018; 187: 242-8. https://doi.org/10.1016/j.drugalcdep.2018.03.008

7. Theunissen M, Peters ML, Schepers J, Schoot DC, Gramke HF, Marcus MA. Prevalence and
دسترس و كاربردى است، در مراكز و كلينيكهاى خدمات

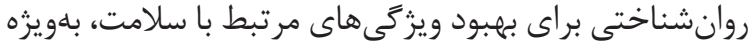

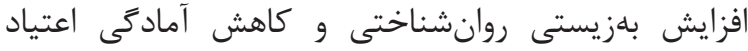

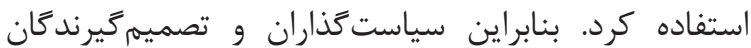
حوزه سلامت، بلهمنظور ارتقاى سلامت دادين دانشجويان دختر دئر

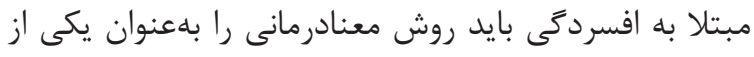

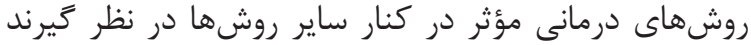

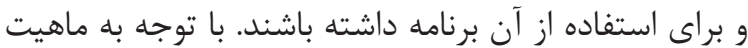

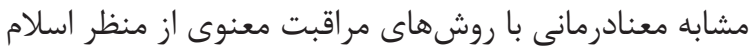

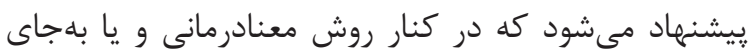

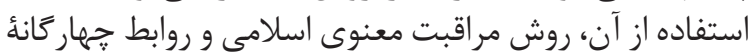

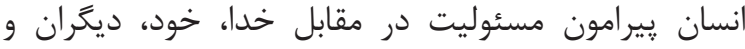

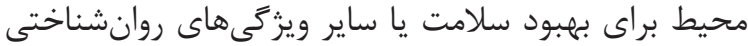

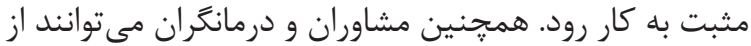

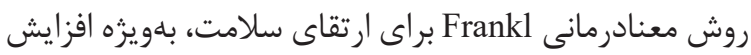
بهزيستى روانشناختى و كاهش آمادگى اعتى اعتياد دانشجويان ساني

predictors of depression and well-being after hysterectomy: An observational study. Eur J Obstet Gynecol Repord Biol. 2017; 217: 94-100. https://doi.org/10.1016/j.ejogrb.2017.08.017

8. Park ER, Kleimann S, Youatt EJ, Lockhart A, Campbell EG, et al. Black and White adults' perspectives on the genetics of nicotine addiction susceptibility. Addict Behav. 2011; 36(7): 769-72 https://doi.org/10.1016/j.addbeh.2011.02.007

9. Buisman-Pijlman FT, Sumracki NM, Gordon JJ, Hull PR, Carter CS, Tops M. Individual differences underlying susceptibility to addiction: Role for the endogenous oxytocin system. Pharmacol Biochem Behav. 2014; 119: 22-38. https://doi. org/10.1016/j.pbb.2013.09.005

10. Levran O, Peles E, Randesi M, Correa da rosa J, Ott J, Rotrosen J, et al. Glutamatergic and GABAergic susceptibility loci for heroin and cocaine addiction in subjects of African and European ancestry. Prog Neuropsychopharmacol Biol Psychiatry. 2016; 64: 118-23. https://doi.org/10.1016/j. pnpbp.2015.08.003

11. Kim J, Stavrositu C. Feelings on Facebook and their correlates with psychological well-being: The moderating role of culture. Computers in Human Behavior. 2018; 89:79-87. https://doi. org/10.1016/j.chb.2018.07.024

12. Sirigatti S, Penzo I, Giannetti E, Casale S, Stefanile C. Relationships between humorism profiles and psychological well-being. Pers Indiv Differ. 2016; 90: 219-24. https://doi.org/10.1016/j. paid.2015.11.011

13. Mousteri V, Daly M, Delaney L. The scarring effect of unemployment on psychological well-being across Europe. Soc Sci Res. 2018; 72: 146-69. 
https://doi.org/10.1016/j.ssresearch.2018.01.007

14. Soetrisno R, Sulistyowati S, Ardhianto A, Hadi $\mathrm{S}$. The effect of logotherapy on the expressions of cortisol, HSP70, Beck Depression Inventory (BDI), and pain scales in advanced cervical cancer patients. Health Care Women Int. 2017; 38(2): 91-9.

15. Kang KA, Shim JS, Jeon DG, Koh MS. The effects of logotherapy on meaning in life and quality of life of late adolescents with terminal cancer. J Korean Acad Nurs. 2009; 39(6): 759-68. https:// doi.org/10.4040/jkan.2009.39.6.759

16. Arzani M. The efficacy of group logotherapy on reducing depression among people addicted to drugs. World Scientific News. 2016; 44: 181-91.

17. Ulrichova M. Logotherapy and existential analysis in counselling psychology as prevention and treatment of burnout syndrome. Social and Behavioral Sciences. 2012; 69: 502-8.

18. Kang K, Im J, Kim H, Kim S, Song M, Sim S. The effect of logotherapy on the suffering, finding meaning, and spiritual well-being of adolescents with terminal cancer. J Korean Acad Child Health Nurs. 2009; 15(2): 136-44. https://doi. org/10.4094/jkachn.2009.15.2.136

19. Krentzman AR, Battle D, Pagano ME, Andrade $\mathrm{FH}$, Bradley JC, et al. The role of religiousness on substance-use disorder treatment outcomes: A comparison between black and white adolescents. J Soc Social Work Res. 2012; 3: 104-28. https://doi.org/10.5243/jsswr.2012.8

20. Niknam M, Madahi ME, Shafiabadi A. Investigating the effectiveness of logotherapy on craving and relapse prevention in women with substance dependency. Health Psychology. 2018; 7(1): 56-73.

21. Mohammadi MR, Akbari AA, Hatami N, Mokri A, Kaviani H, et al. Effectiveness of grouped spiritual psychotherapy on patients with opium using disorder. Hakim Research J. 2011; 14(3): 144-50.

22. Saffarinia M, Dortaj A. Effect of group logotherapy on life expectancy and mental and social wellbeing of the female elderly residents of nursing homes in Dubai. Salmand Iranian J Ageing. 2018; 12(4): 482-93.
23. Soleimani E, Khosravian B. The effectiveness of group Logotherapy on marital satisfaction and psychological well-being of maladjusted couples. Family Counseling and Psychotherapy. 2017; 6(2): 1-19.

24. Shojaee A, Eskandarpour B. A study of the effectiveness of Frankel's logotherapy training on psychological well-being and happiness of students. J School Psychol. 2016; 5(2): 71-91.

25. Hassani M, Shohoudi M, Mirghasemi SJ. The study of relationships between moral intelligence and self-efficiency with psychological well-being among martyr's wife and offspring of Urmia University. Iran J Bioethics. 2016; 6(19): 155-180.

26. Mohabbat Bahar S, Golzari M, Akbari M E, Moradi-Joo M. Effectiveness of group logo therapy on decreasing hopelessness in women with breast cancer. Iran J Breast Dis. 2015; 8(1): 4958.

27. Beck AT, Clarck DA. Anxiety and depression: An information processing perspective. Anxiety Res, 1988;1:23-36.

28. Akbari SA, Vameghi R, Sajedi F, Sajjadi H, Majd HA, Hajighasemali S. Relationship between Socio-Economic Status, Perceived Stress, Social Support and Domestic Violence With Women s Depression In Reproductive Age Using Path Analysis.

29. Weed N, Butcher JN, Mckenna T, Ben-Porath YS. New measures for assessing alcohol and other drug problems with MMPI-2: APS and AAS. J Pers Assess. 1992;58(2):389-404.

30. Mohammadkhani Sh, Yeganeh T, Karimpour K. Role of religious orientation and self-control in prediction of drug addiction potential. J Health Care. 2015; 17(3): 248-59.

31. Cho S. Effects of logo-autobiography program on meaning in life and mental health in the wives of alcoholics. Asian Nurs Res. 2008; 2(2): 129-39.

32. Akbari M, Najafi S, Nadrian H. The relationship between social capital perceived social support and the women's mental health in Sanandaj: a community-based study. Iran J Health Educ Health Promot. 2017; 5(3): 155-63. 